\title{
PENGGABUNGAN FORWARD SELECTION UNTUK PEMILIHAN FITUR PADA PREDIKSI BIMBINGAN KONSELING SISWA DENGAN MENGGUNAKAN ALGORITMA NAÏVE BAYES
}

\author{
M. Rudi Fanani \\ e-mail : m.rudifanani@itsnupekalongan.ac.id \\ S1 Teknologi Informasi, Institut Teknologi dan Sains Nahdlatul Ulama Pekalongan \\ Jl. Karangdowo No. 09 Kedungwuni Kab. Pekalongan Jawa Tengah 51173 Telp: (0825) 7831614
}

\begin{abstract}
Abstrak
Kegiatan bimbingan dan konseling di sekolah adalah cara membantu siswa dalam mengembangkan kepribadian, sikap sosial, pembelajaran, pengembangan karir dan perencanaan. Kegiatan Bimbingan dan Konseling juga berperan dalam menyikapi perilaku menyimpang para siswa yang ditunjukkan para siswa baik masih berada dalam limgkup sekolah dan juga luar sekolah. Dalam menentukan kegiatan bimbingan konseling, guru bimbingan konseling dapat memberikan penilaian sejauh mana peningkatan perilaku siswa di sekolah. Namun penentuan rekomendasi bimbingan dan konseling kurang akurat dikarenakan harus berdasarkan pengetahuan dan pengolahan banyaknya data yang ada sehingga diperlukan sebuah perhitungan yang menerapkan metode prediksi dengan teknik data mining. Salah satu teknik data mining adalah Nä̈ve Bayes yang menggunakan teknik klasifikasi, yang mampu menghasilkan nilai akurasi sebesar $94.55 \%$ dan juga dalam penelitian menerapkan fitur seleksi yang digunakan sebagau pemilihan fitur yang berpengaruh terhadap klasifikasi guna meningkatkan akurasi. Fitur seleksi yang digunakan adalah Forward Selection yang mampu meningkatkan akurasi menjadi $94.84 \%$ dengan membuang beberapa fitur yang tidak relevan terhadap klasifikasi dan menjadikan hasil yang lebih baik daripada menggunakan metode Nä̈ve Bayes saja
\end{abstract}

Kata kunci : Bimbingan Konseling, Sekolah, Nä̈ve Bayes, Forward Selection, Klasifikasi, Prediksi

\section{Pendahuluan}

Kegiatan bimbingan dan konseling di sekolah adalah cara membantu siswa dalam mengembangkan kepribadian, sikap sosial, pembelajaran, pengembangan karir dan perencanaan. kegiatan bimbingan dan konseling memberikan cara mengembangkan diri siswa secara pribadi dan kelompok, yang menyesuaikan dengan, potensi, perkembangan, bakat, kebutuhan, minat, dan lain sebagainya. Kegiatan ini juga memberikan bantuan untuk mengatasi hambatan juga kelemahan dan masalah yang dihadapi siswa. Awal mula diselenggarakan bimbingan dan konseling di sekolah bukan dari ketentuan dari atas ataupun landasan hukum, tapi yang lebih penting yaitu yang berhubungan dengan cara memfasilitasi siswa yang selanjutnya disebut dengan konseli, agar potensi diri siswa dapat berkembang atau perkmbangan tersebut dapat dicapai (berhubungan aspek emosi, intelektual, fisik, moral dan sosial) [1].

Kegiatan bimbingan dan konseling tidak bisa dipisahkan dari bidang pendidikan. Dalam melaksanakan tidak boleh secara bebas dan gampang, banyak kekeliruan yang timbul dalam kegiatan bimbingan dan konseling yang sudah berjalan, banyak yang beranggapan polisi dalam sekolah merupakan kegiatan dari bimbingan dan konseling maupun anggapan yang berbeda dari fungsi kegiatan bimbingan dan konseling. semua aturan pendidikan yang ada harus dilengkapi dengan Bimbingan dan konseling yang ada di sekolah, untuk melancarkan fungsi serta tugas pendidikan dengan benar, sehingga para penyelenggara pendidikan mempunyai relasi yang baik, secara umum diperlukan penanganan individu untuk mencapai tujuan pendidikan yang lebih baik. Tidak akan tercapai tujuan pendidikan jika hanya dengan cara pengajaran oleh guru, tetapi juga diperlukan program kegiatan bimbingan dan konseling yang terdapat didalam PP No. 38/1992 Pasal I ayat 2 tentang tenaga Kependidikan, yang berisi: "Tenaga pendidik adalah tenaga kependidikan yang bertugas membimbing, mengajar dan atau melatih peserta didik" [2].

Dari penjelasan di atas, jelas bahwa melakukan prediksi bimbingan konseling diperlukan sebuah perhitungan yang menerapkan metode prediksi dan juga merupakan hal yang penting bagi sekolah untuk menentukan kebijaksaan strategis, dan sekolah bisa menggunakan mekanisme pendukung seperti pengawasan, nasihat, orientasi dan lain-lain.

Naïve Bayes adalah perhitungan probabilitas dengan metode pengklasifikasian. Model ini mudah untuk dibangun dan tidak complicated, sehingga dianggap tepat untuk database yang berukuran kecil sampai 
berukuran besar. Algoritma Naïve Bayes menghitung probabilitas kejadian masa datang dari kejadian sebelumnya dimana masingmasing variabel dianggap tidak saling tergantung [3]. Kelebihan dari algoritma Naïve Bayes adalah sederhana tapi mempunyai akurasi yang tinggi meskipun menggunakan data yang sedikit [4]. Sedangkan kelemahan dalam Naive Bayes, yaitu prediksi hasil probabilitas berjalan tidak optimal serta kurangnya pemilihan fitur yang relevan terhadap klasifikasi sehingga akurasi menjadi rendah Hal tersebut dapat diatasi dengan cara pemilihan fitur yang berguna untuk meningkatkan akurasi [5].

Algoritma Forward Selection merupakan salah satu seleksi fitur yang dilakukan sebelum pemrosesan dalam klasifikasi yang terbukti efektif digunakan untuk memecahkan masalah pemilihan fitur yang relevan dalam suatu data(Rakhman \& Sutanto, 2018). Forward Selection dijalankan mengunakan pemilihan fitur yang relevan untuk data yang berpengaruh terhadap hasil klasifikasi. Juga dalam mengurangi dimensi data dan sebagai peningkatan efisien dan efektifitas kerja algoritma klasifikasi [6].

\section{Metode Penelitian}

Kerangka penelitian ini terdiri dari beberapa tahap seperti terlihat pada Gambar 1 . Permasalahan pada penelitian ini adalah mengetahui seberapa meningkat akurasi algoritma Nä̈ve Bayes dengan Forward Selection. Terhadap data bimbingan konsling. Untuk mengembangkan aplikasi berdasarkan model yang dibuat, digunakan RapidMiner

5.3.013. Kemudian dilakukan pengujian dengan Cross validation, hasil ditunjukkan oleh Confusion matrix. Dibawah ini adalah kerangka pemikiran dalam bentuk bagan

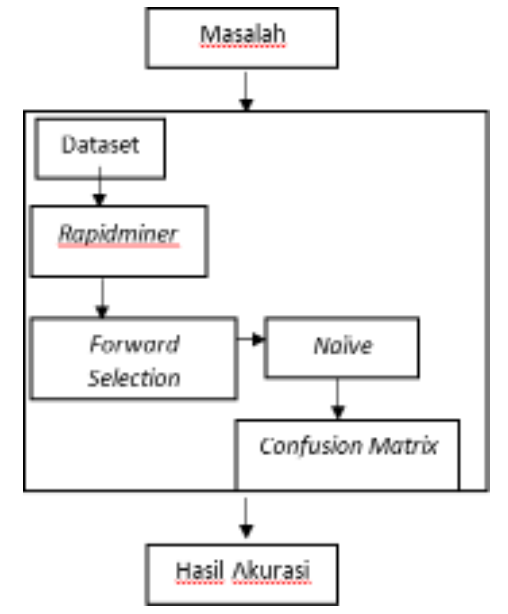

Gambar 1 Kerangka Penelitan
Nä̈ve Bayes dapat digunakan untuk memprediksi probabilitas suatu kelas, akan tetapi dengan adanya banyak atribut dalam data, kinerja dari algoritma Nä̈ve Bayes menjadi kurang optimal dan juga mengurangi tingkat akurasi, maka diperlukan pemilihan atribut yang signifikan terhadap hasil klasifikasi menggunakan Forward Selection agar akurasi lebih meningkat.

Penelitian ini menggunakan data berupa dokumen laporan bimbingan konseling siswa SMK NU Ma'arif Tirto berisi 329 record dan terdiri dari variabel hubungan sosial dan berorganisasi, keadaan kehidupan ekonomi, rekreasi dan hobi, kehidupan keluarga, agama dan moral, kesehatan, pribadi, penyesuaian sekolah, penyesuaian kurikulum, dan masa depan pendidikan. Dokumen ini akan digunakan untuk data eksperimen memprediksi bimbingan konseling.

Jenis penelitian ini adalah eksperimen. Penelitian ini menggunakan data sekunder. Data sekunder berupa data bimbingan konseling yang dilakukan guru BK Bawon Sulastri yang telah berpengalaman dan berkompeten di bidangnya selama 8 tahun, tetapi tidak diterbitkan. Dari jumlah 329 record, 102 record menghasilkan label Diharuskan Konseling dan 227 record menghasilkan Tidak diharuskan konseling.

Untuk memberikan gambaran yang jelas tentang data dalam penelitian ini, maka peneliti memberikan definisi terhadap variabel yang akan diangkat dalam penelitian ini agar pemahaman dan persepsi menjadi satu.

Nama variabel Masalah Hubungan Sosial dan Berorganisasi, Masalah Keadaaan Kehidupan Ekonomi, Masalah Rekreasi dan Hobi, Masalah Kehidupan Keluarga, Masalah Agama dan Moral, Masalah Kesehatan, Masalah Penyesuaian Sekolah, Masalah Penyesuaian Terhadap Kurikulum, Masalah Masa Depan Pendidikan, Masalah Pribadi dengan indikator penialaian Sangat Baik, Baik, Cukup Baik, Cukup, Kurang dan Kurang Sekali.

Penelitian ini menggunakan pengukuran evaluasi yaitu confusion matrix yang mempunyai tujuan guna mempermudah dalam analisis performa algoritma, dikarenakan confusion matrix bias menampilkan informasi berbentuk angka, sehingga bias dilkaukan perhitungan rasio keberhasilan klasifikasi. Confusion matrix adalah salah satu alat ukur 
"Masalah Penyesuaian Terhadap Kurikulum" dan "Masalah Masa Depan Pendidikan". Dilihat dari nilai weight yang bernilai 1 (satu) artinya signifikan, dan nilai weight 0 artinya tidak signifikan atau atribut yang tidak berpengaruh, dalam hal ini atribut "Masalah Pribadi". hal ini menjelaskan bahwa dalam perhitungan bimbingan dan konseling dapat diprediksi secara optimal melalui 9 atribut yang dipilih melalui Forward Selection.

\section{Kesimpulan}

Dari hasil eksperimen dan evaluasi penelitian dapat disimpulkan bahwa akurasi metode Nä̈ve Bayes pada bimbingan konseling siswa mencapai $94.55 \%$. setelah dilakukan penambahan fitur seleksi untuk memilih atribut yang relevan terhadap hasil klasifikasi didapatkan nilai akurasi yang lebih tinggi yaitu 94.84\%. Dari 10 variabel dari data Bimbingan Konseling Siswa terdapat 9 atribut yang signifikan, antara lain: "Masalah Hubungan Sosial dan Berorganisasi", "Masalah Keadaan Kehidupan Ekonomi", "Masalah Rekreasi dan Hobi", "Masalah Kehidupan Keluarga", "Masalah Agama dan Moral", "Masalah Kesehatan", "Masalah Penyesuaian Sekolah", "Masalah Penyesuaian Terhadap Kurikulum" dan "Masalah Masa Depan Pendidikan". Maka dapat disimpulkan pengujian data bimbingan dan konseling siswa menggunakan metode Naïve Bayes berbasis Forward Selection terbukti dapat meningkatkan tingkat akurasi dengan adanya penggunaan fitur seleksi tersebut, dibandingkan dengan metode Nä̈ve Bayes tunggal, yang ditandai dengan peningkatan nilai akurasi sebesar $0.29 \%$.

\section{Daftar Pustaka}

[1] Subiharta and D. M. Yuwana, "Pengaruh Penggunaan Bahan Tempat Air dan Letak Telur di Dalam Mesin Tetas yang Berpemanas Listrik Pada Penetasan Itik Tegal," in Kedaulatan Pangan dan Energi, Madura, 2012.

[2] R. Dewanti, Y. and S. , "Pengaruh Bobot dan Frekuensi Pemutaran Telur Terhadap Fertilitas, Daya Tetas, dan Bobot Tetas Itik Lokal," Jurnal Peternakan, vol. I, no. 38, pp. 16-20, 2014.

[3] J. Lieng, I. P. E. N. Kencana and T. B. Oka, "Analisis Sentimen Menggunakan Metode Naive Bayes Classifier dengan
Seleksi Fitur Chi Square," Jurnal Matematika, vol. 3, no. 2303-1751, pp. 92-99, 2014.

[4] R. S. Wardani and P. , "Model Pengambilan Keputusan Dalam Prediksi Kasus Tuberkolosis Menggunakan Regresi Logistik Berbasis Backward Elimination," Teknik Informatika, pp. 16.

[5] M. Dash and H. Liu, "Feature Selection for Classification," ntelligent Data Analys, vol. 1, no. 1-4, pp. 131-156, 1997.

[6] N. W. Ispriyani, A. Nilogiri and D. Arifianto, "Klasifikasi Penyakit Salmonellosis pada Itik Pedaging Menggunakan Metode Naive Bayes," Universitas Muhammadiyah Jember, Jember, n.y..

[7] S. Puspitaningsih, "Implementasi Metode Naive Bayes pada Sistem Diagnosa Penyakit Ikan Lele," UIN Maulana Malik Maghribi, Malang Jawa Timur, 2019.

[8] Rakhman, A., \& Sutanto, A. (2018). Analisa Sistem Informasi Geografis Tempat Laundry Berbasis Android. Smart Comp: Jurnalnya Orang Pintar Komputer, 7(1).

[9] Daniati, "Klasifikasi Jenis Bimbingan dan Konseling Siswa SMK N 1 Kediri Menggunakan Naive Bayes Classifier dan Nearest Neighbour," Jurnal Engineering, vol. 01, pp. 22-27, 2011.

[10] Rakhman, A., \& Sabanise, A. Y. F. (2019). Sistem Informasi Stok Kebutuhan Darah Pada Palang Merah Indonesia Dengan Metode Weighted Moving Average. Syntax Literate; Jurnal Ilmiah Indonesia, 4(7), 24-32.

[11] F. Gorunescu, Data Mining Concepts, Models, and Techniques, Berlin: 